\title{
Risk Factors and Outcome of Acute Kidney Injury after Congenital Heart Surgery
}

Sir,

I read the article "Risk factors and outcome of acute kidney injury after congenital heart surgery: A prospective observational study" by Amini et al. with interest. ${ }^{[1]}$ While this article highlights the importance of recognition and assessment of acute kidney injury (AKI) in children following congenital heart surgery, there are many things that the authors failed to notice in their study.

As shown in your table 3, in the manuscript, the authors mentioned that a total of 96 children underwent surgery in the group $\mathrm{AKI}$, while 227 underwent surgery under cardiopulmonary bypass (CPB) and are within the group with "no AKI." However, what the authors failed to demonstrate is the proportion of children who did not receive $\mathrm{CPB}$, but still ended up having AKI (which seemed to be a total of 54 out of 150).

Furthermore, the role of vasoconstrictors in selectively compromising mesenteric and renal circulation is well known. While the inotropic score was briefly mentioned in methodology, this particularly important factor was not assessed anywhere else in the article, nor mentioned for its relevance to the study.

It is also interesting to note that while the authors have used an appropriate definition for AKI in the methodology section, they failed to define the various management schemes for different categories of AKI. Furthermore, the renal replacement therapy (seen in three children) was not expanded fully, other than a mention of "dialysis." We also know that while some of these children with severe form of AKI can go on to receive hemodialysis for a period of time, there are also a significant number of children who are helped electively, and prophylactically by peritoneal dialysis, and in some units, with continuous venovenous filtration. ${ }^{[2]}$ These would help in understanding the spectrum of AKI as well as the efficiency of management, thereby highlighting the clinical relevance of some of the postoperative variables including morbidity they have assessed in this study.

\section{Financial support and sponsorship}

Nil.

\section{Conflicts of interest}

There are no conflicts of interest.

Nagarajan Muthialu

Department of Cardiothoracic Surgery, Great Ormond Street Hospital for Children, London, UK

Address for correspondence: Mr. Nagarajan Muthialu, Department of Cardiothoracic Surgery, Great Ormond Street Hospital for Children, Great Ormond Street, London WC1N 3JH, UK. E-mail: nagarajan.muthialu@gosh.nhs.uk

\section{References}

1. Amini S, Abbaspour H, Morovatdar N, Robabi HN, Soltani G, Tashnizi MA, et al. Risk factors and outcome of acute kidney injury after congenital heart surgery: A Prospective observational study. Indian 
J Crit Care Med 2017;21:847-51.

2. Tóth R, Breuer T, Cserép Z, Lex D, Fazekas L, Sápi E, et al. Acute kidney injury is associated with higher morbidity and resource utilization in pediatric patients undergoing heart surgery. Ann Thorac Surg 2012;93:1984-90.

This is an open access journal, and articles are distributed under the terms of the Creative Commons Attribution-NonCommercial-ShareAlike 4.0 License, which allows others to remix, tweak, and build upon the work non-commercially, as long as appropriate credit is given and the new creations are licensed under the identical terms.

\begin{tabular}{|l|l|}
\hline \multicolumn{3}{|c|}{ Access this article online } \\
\hline Quick Response Code: & Website: \\
& www.ijccm.org \\
& \\
\end{tabular}

How to cite this article: Muthialu N. Risk factors and outcome of acute kidney injury after congenital heart surgery. Indian J Crit Care Med 2018;22:198-9.

(C) 2018 Indian Journal of Critical Care Medicine | Published by Wolters Kluwer - Medknow 